\title{
Measurement Of Shear Fatigue Strength Of Fiber Glass Epoxy Laminates \& Carbon Chapstan Laminates Using Fatigue Test Rig
}

\author{
B.Suresh Babu ${ }^{1,}$ Pns Srinivas ${ }^{2}$ \\ 1. Associate professor of mechanical department in Sri vasavi institute of engineering \& technology, affiliated to \\ JNTUK Nandamuru, PedanaMandal, Krishna Dist,AP - 521369 \\ 2. Asst professor of mechanical department in Sri vasavi institute of engineering \& technology, affiliated to \\ JNTUK Nandamuru, PedanaMandal, Krishna Dist, AP - 521369
}

\begin{abstract}
The present research work mainly is focusing on measurement of shear fatigue strength of glass fiber epoxy laminates \&chaps tan e-glass epoxy laminates on unconventional fatigue testing machine \& this machine is standardized according to ASTM -6944(1990) standards. The study of DOE (Design of experiments) is exclusively done on theoretical\& experimental value analysis. This work is further used to develop of manufacturing process and establishing critical test procedures for the glass fiber \&epoxy laminate composite materials to be used in defence research, marine, oil refinery units \& power plant equipment's. This research work played an important role in estimation of stiffness of the laminate which in turn helps for the testing to evaluate the stiffness of the laminate for further mathematical analysis. The evaluating stiffness degradation data of the various composite materials by theoretical calculation is compared with experimental value analysisand from which the relations of mechanical properties are derived. This reduction in stiffness can further be improved by advanced manufacturing process such as compressor moulding, macro spheremoulding\& auto clave moulding and the results obtained from the analytical testing are used to calibrate the load transducers. The load transducers are calibrated according to ASTM 1577(1994) standards by which we can validate the results \& apply as bench mark for other fatigue testing materials. The data acquisition system from standard manufacturer of model TSI-608 which exactly meets requirements. A continuous plot of time verses load could be obtainedWe can say that the required data can be generated as per expectations, which could be utilized to establish the fatigue failure behavior any kind of composite laminate.
\end{abstract}

Keywords: - stiffness, load transducers, ASTM, analysis, composite laminates, chap stan laminates

\section{INTRODUCTION}

The laminated composite materials usage is increasing in all sorts of engineering applications due to high specific strength and stiffness. Fiber reinforced composite materials are selected for weight critical applications and these materials have good rating as per the fatigue failure is concerned. Present work is aimed to analyze the behavior of each laminate under the flexural fatigue test rig. Therefore here different types of composite materials are selected for test specimens. For this load transducer, the accuracy level required in transducer body is an important task. As selection of a transducer and work for its consistency is important consideration. Therefore a sensitive, consistently strong transducer to meet the axial tension-compression fatigue loading is required. (2)To provide dynamic sensibility to the transducer, foil type resistance strain gauges are used. The geometric shape of the load transducer is an important factor to be considered, to impart sufficient strain to the strain gauge, which in turn generates a noticeable signal with noticeable amplitude in the form of a voltage signal. The dynamic nature of loading could be read in the form of a signal is possible only with the isoelastic type of strain gauges. In order to get the information after which it fails software is created which produces the waves depicting the response of the transducer to the loads applied on it. The present project work mainly is focusing on development of manufacturing process and establishing critical test procedures for the polymer reinforced composite materials to be used in certain engineering applications.

\section{FATIGUE}

The flexural fatigue failure in laminated composite materials is a very common failure mode in most of the FRP components. As reinforced polymers used in weight critical applications, often over designed to compensate fatigue failure lead to the increase in weight which in turn hampers the objective of designer. In this connection the investigation on flexural fatigue failure behavior of laminate to be used in the component is very important. As standard equipment and test procedures are not available. 


\section{2 .1 Fatigue}

When a material is subjected to repeated stresses or loads, it fails below the yield stress. Such type of failure of a material is known as fatigue.

\subsubsection{Characteristics of Fatigue}

$\square$ In metals and alloys, the process starts with dislocation movement, eventually forming persistent slip bands that nucleate short cracks.

Fatigue is a stochastic process, often showing considerable scatter even in controlled environments.

The greater the applied stress range, the shorter the life.

Fatigue life scatter tends to increase for longer fatigue lives.

Damage is cumulative. Materials do not recover when rested.

Fatigue life is influenced by a variety of factors, such as temperature, surface finish microstructure, presence of oxidizing or inert chemicals, residual stresses, contact, etc.

\subsection{Flexural Fatigue}

When a material is subjected to variable bending stresses or loads, it fails belowthe yield stress.

\subsection{Fatigue Test Applications}

Fatigue testing helps determine how a material or product design will perform under anticipated service conditions. Many fatigue tests repeat the application of loads by controlling stress that is repeated for millions of cycles. In many engineering applications, products or materials experience vibration or oscillatory forces so it's important to predict and prove fatigue life, or cycles to failure under loading conditions.

There are as many specialized fatigue testing protocols or test methods as there are products designed for fatigue applications. A few are supported as industry standard test methods but most designs are unique so machines are configured to match their needs. Metals and metal substitutes such as advanced composites are commonly used for fatigue resistant designs, so standards are more available. Low Cycle Fatigue (LCF) or strain controlled tests, High Cycle Fatigue (HCF) or load controlled tests, and even Random Spectrum tests are now common. Medical implants for orthopedic and intravascular use are also widely tested to FDA requirements.(4)

\subsection{Mechanism of Fatigue Failure in Laminated Composites}

"Composites are a combination of a reinforcement fiber in a polymer resin matrix, where the reinforcement has an aspect ratio that enables the transfer of load between fiber, and the fibers are chemically bonded to the resin matrix. This precise definition accounts for the attributes of composites as an engineering material and differentiates them from a lot of combined materials having a lesser degree of synergy between the individual components.

Cyclic deformation process in fiber-reinforced materials differs widely from those in homogenous isotropic materials. For example, crack nucleation plays a significant role in the latter; in the former, cracks and failure zones are often formed in the very first few cycles. In fact, there are often voids and defects in the material even before cycling begins. Secondly, fiber reinforced materials are characterized by a high degree of anisotropy; the ratio of longitudinal to transverse moduli varies from about 5 for glass fiber-polymers to about 25 for graphite or boron fiber-polymers. The stress field around a flaw in such a highly anisotropic medium is significantly different from one in isotropic material consequently, while homogeneous isotropic materials usually fail in fatigue by the nucleation of a crack which propagates in single mode, composite materials generally exhibit a variety of failure modes including matrix crazing or micro cracking, individual fiber failures resulting from statistically distributed flaw strengths, debonding, delamation, void growth etc. In addition, several of these failure modes are generally present at any given time prior to failure.

Fiber reinforced composites are subjected to cyclic loading, it is not clear whether there would be reactions at the entire glass polymer interface due to moisture absorption through the polymer layer, or whether matrix micro cracks, alone (resulting from cyclic failure), would provide a conduit for preferential attack by water vapor over a localized area on the fibers at the crack front leading to further crack growth and eventual fatigue failure of the composite.(5) From this description it is clearly evident that the fatigue life of composite laminate is influenced by many factors. The degree of significance of the above mentioned factors cannot be established with confidence. This present work is aimed at establishing a suitable test procedure for the fatigue life characteristics with a low cost test rig to meet the real time design requirements. The features of the test rig are explained in following script.

As the test proceeds for so many number of load cycles (is of order $10^{6}$ cycles) the generated from dynamic transducer cannot record manually. Then the signal conditioning system coupled with analog to digital 
conversion electronic circuit and the data logging software incorporated in the test rig. This logged data can be analyzed to establish the failure behavior and fatigue life characteristics of the composite laminates. This method of testing can be utilized for fatigue applications.

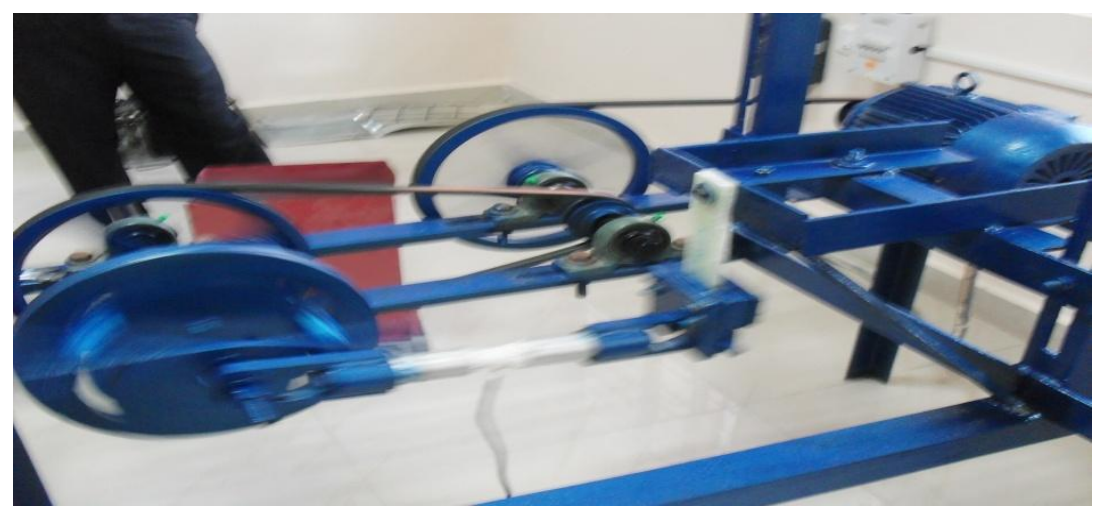

Fig 1.Positioning of composite material in vertical \& horizontal directions in Pictorial view of Fatigue Test Rig

In the above testing apparatus the positioning of the composite is arranged in vertical direction. By changing the fixture or holding device of the composite material it can place in horizontal direction

The Bending fatigue test rig is capable of simulating bending fatigue load of 0 to $1000 \mathrm{~N}$ on the test coupon at a frequency of 120 cycles per minute. The king pin is assembled to the dovetail mechanism which could be fixed at desired eccentricity. That provides desired bending force on the specimen.

\subsubsection{Important Components of Test Rig}

i) Load cell

ii) Specimen holding beam

iii) Dovetail assembly

iv) Induction motor

v) Adjustable columns(Sliding )

vi) Electronic circuit(Signal Conditioning System)

vii) Data acquisition software

viii) Connector from the electronic circuit to the cmputer.

ix) Printer

\subsubsection{Working Principle of Test Rig}

The working of the equipment is as follows, the circular object on which the hinge is fixed is termed as crank and this is connected to motor of 1HP power specification. The hinge eccentricity from the center of the crank is directly proportional to the deflection of the composite specimen. And this deflection resisting force is experienced by the linkage which is equipped with strain measurement.

The strain gauge bonded to the linkage (load cell) elongates and contracts along with the load cell which in turn imbalances the balanced bridge circuit connected to the strain gauge.

The output voltage of the bridge circuit is directly proportional to the deflection load of the composite specimen. As crank rotates with the constant rpm of 94 the strain measuring system develops voltage proportional to the degree of deflection. The voltage waveform is a pure sine wave. The cyclic load applied to the composite specimen generates a fatigue crack at the fixed end A from the Fig. 2.2.

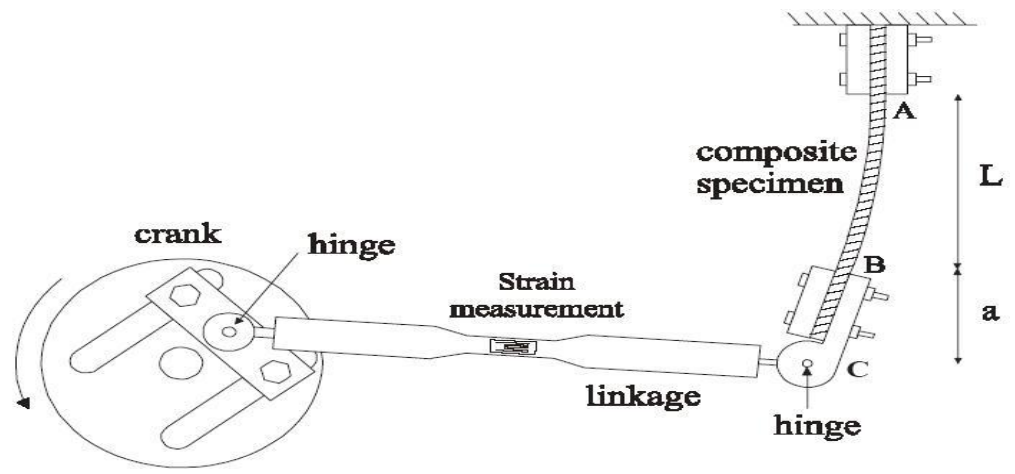

Fig.2. Schematic line diagram of Hinge Eccentricity, Load Cell and Specimen Holding Arrangement 
Which in turn reduces the stiffness of the composite specimen and that is been clearly reflected on the voltage output from the strain measuring bridge circuit. The amplitude of wave form decreases as the damage progresses in the due course as the cyclic loading proceeds from 0 cycles to $\mathrm{n}$ number of cycles. This diminishing wave form reveals the health of the laminate as the time progresses. The recording of data in digital form could lead to analyze the fatigue damage pattern accurately.

\subsubsection{Specifications of the Test Rig}

Bending load capacity 0 to $1200 \mathrm{~N}$

Frequency 1.57 to 10 RPS

Specimen specifications $200 \times 40 \times 6 \mathrm{~mm}$

Eccentricity 0 to $250 \mathrm{~mm}$

\section{LOAD CELL}

Introduction: Load cell is a very important component which senses load and delivers a voltage analog signal, which isproportional to the intensity of load. This consists of a metallic body designed to meet the requirements of the working load range, generally it is made of aluminum alloy. The foil type strain gages are fixed to the body of the load cell. When the body of the load cell is subjected to load, the strain induced is transmitted to the strain gage. Dynamic load sensor (LOAD CELL) is important component of the test rig.

\section{Selection of a Transducer:}

The selection of the correct load transducer is followed by the following steps:

1. Material selection.

2. Proposing geometric models.

* High sensitive type

* Medium sensitive type

The material selection is based on the elastic property that is young's modulus. This should be capable of providing sufficient elastic strain for a given load application range. As per the present load application range of $0-1000 \mathrm{~N}$ the material selected for this application is an aluminum alloy of Young's modulus 70 GPA.

\subsection{High Sensitive Type Load Cells \\ 3.1.1Ring type load cell:}

The ring type load cell body is made of Aluminum. This is proposed in view of simulating more strainin the segments of hollow cylindrical segments, when the body is subjected to tensile and compressive stress. The ring type load cell is furnished in Fig. 4.1. The ring portion of the load cell body is first part of the body to undergo strain by virtue of changing its shape, which is a perfect circular to oval shape. When the load cell is subjected to tensile load, the inner portion of the body is subjected to tensile strain and the outer portion is subjected to compressive strain. This is proposed in the view of gaining strong signal from the bridge circuit.

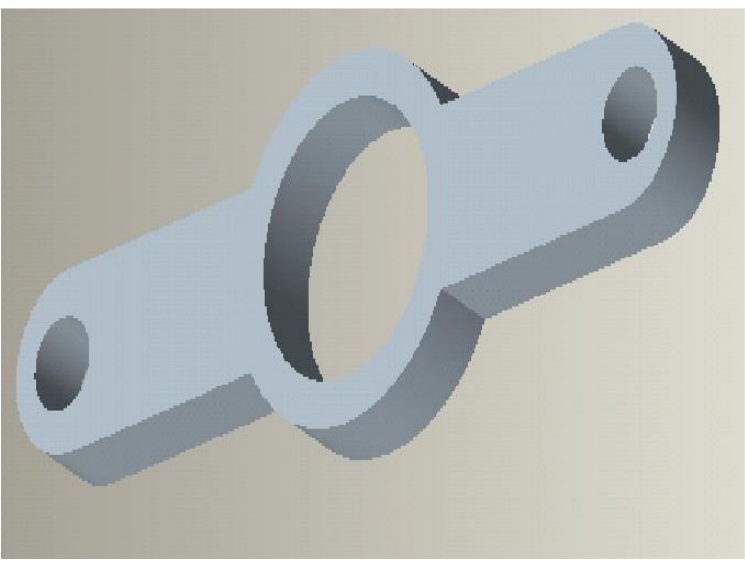

Fig. 3. Ring Type Load Cell

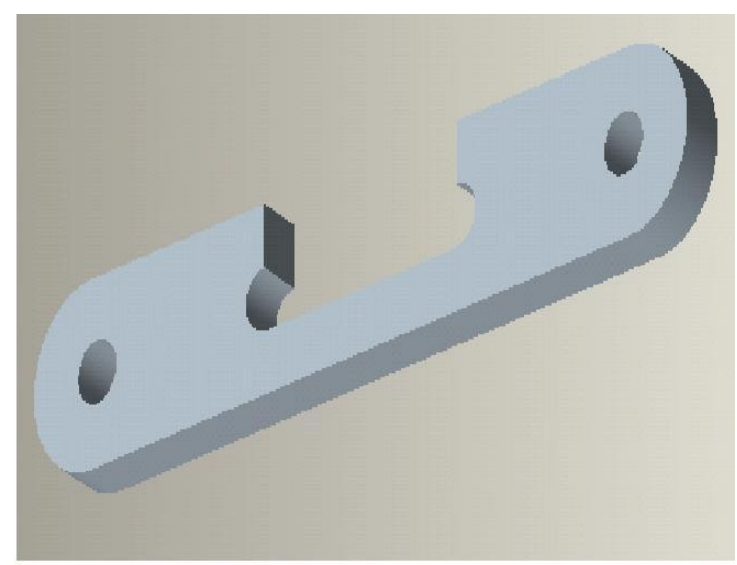

Fig. 4. C-Type Load Cell

3.1.2 "C" type load cell: The C type load cell is supposed to be strained in the thinner portion of the body. 


\subsection{Medium Sensitive Type Load Cells}

3.2.1 H-Type Load Cell: " $\mathrm{H}$ " type of load cell body is proposed to meet the dynamic loading situation of the flexural fatigue test rig.

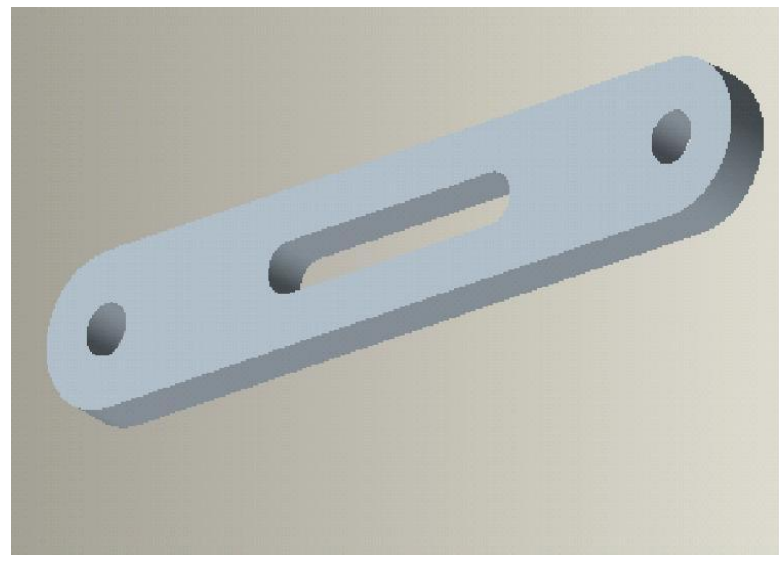

Fig.5. H-Type Load Cell

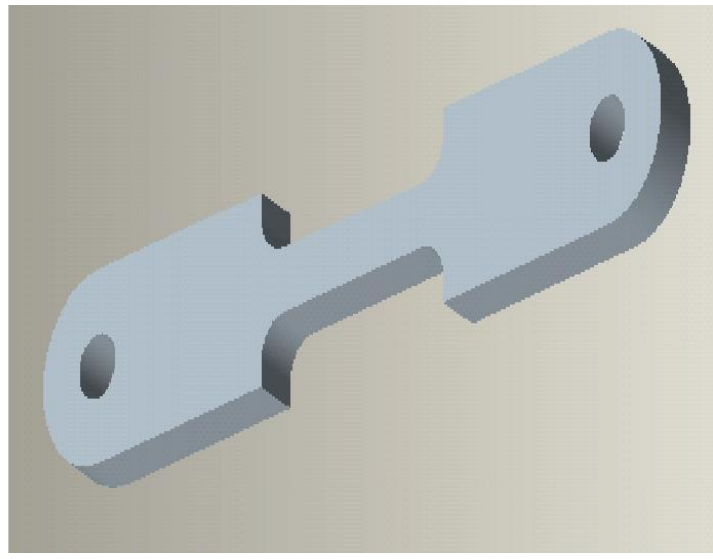

Fig.6.- I Type Load Cell

3.2.2"I" Type Load Cell:"I" type load cell having the thinnest gauge portion among the proposed load cell body models.

3.2.3 Pillar Type Load Cell: Among the load cell bodies proposed are observed carefully, and then the cylindrical gauge portionis proposed in view of achieving same strain on the gage bonding area of the load cell body.

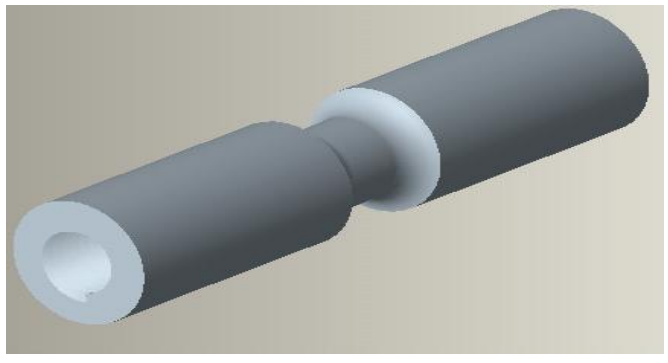

Fig.7. Pillar Type Load Cell

\section{ELECTRONIC CIRCUIT}

4. Introduction: The electronic circuits are also very important a component of system and this are capable of amplifyingthe analog signal coming from the load cell and digitizes it to have provision of storing the data accurately to analyzing the data regarding stiffness degradation behavior of the specimen.

\subsection{Electronic Circuit for Signal Conditioning and Data Logging Systems}

Dynamic load sensing is a mechanism, which senses the fluctuating loads with respect to time. A load cell (strain gage type) is a transducer, which senses the varying loads and changes its dimensions proportional to stress. The strain gage is incorporated in the bridge circuit and change in its resistance due to strain will unbalance the bridge. This unbalance voltage is amplified by the instrumentation amplifier. (12)

A real time application of dynamic load sensing which convert the analog voltage from instrumentation amplifier to digital voltage by an ADC. This digital voltage is fed to computer via USB port. The sensing element which is an electrical type load cell senses the strain. The strain gage is glued to the load cell. The resistance of the load cell is $350 \mathrm{ohms}$ resistors. This bridge is excited by the 10volts DC supply. Under no load condition i.e., when strain gage is not strained the bridge is under balanced condition. When load is applied on the load cell, the dimensions of strain gage gets changed thereby its resistance is varied. The amount of strain applied on the load cell proportionally changes the resistance of the strain gage. This change in resistance causes the bridge to unbalance. (13)This unbalanced voltage is proportional to the load applied on the specimen.

In the first stage of amplification the gain has been limited to only 100 even though the capability of AD620AN is having a gain of 1000. This decision has been taken by carefully observing characteristics of the instrumentation amplifier to avoid unnecessary interference. The typical circuit to the signal conditioning system is shown in following Fig. 5.1. 


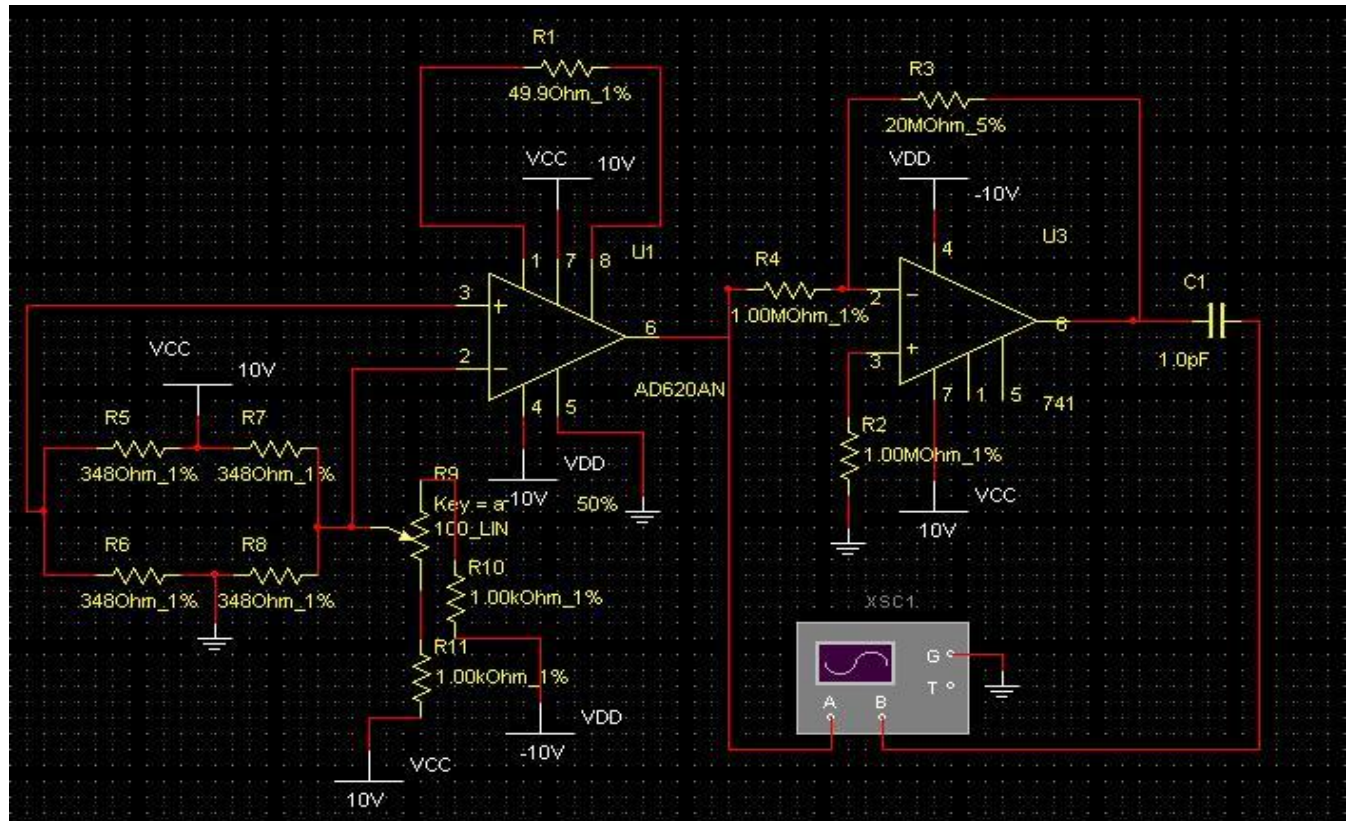

Fig 8.Signal conditioning circuit layout

\section{Introduction to Flexural Fatigue Experimentation}

\section{EXPERIMENTATION}

The present experimentation is aimed to understand the flexural fatigue behavior under high cycle fatigue conditions of Glass Fiber Epoxy, Chapsten E-Glass Epoxy and Glass Fiber Polyester Epoxy laminates. Before getting into the experimentation work, the evaluation of mechanical properties of glass fiber epoxy laminates is very important.

A laminates of $200 \mathrm{~mm}$ length, $40 \mathrm{~mm}$ width and $6 \mathrm{~mm}$ thickness were prepared. And from this laminates tensile tests were conducted for calculating the starting load on specimens for conducting fatigue test.

\subsection{Tensile Tests}

Tensile tests are performed on the specimens and the tabulated values are furnished in table 6.1. The specifications of the test specimen are $200 \mathrm{~mm}$ length, $6 \mathrm{~mm}$ thickness and $40 \mathrm{~mm}$ width. Following figures related to tensile tests conducted on various specimens. The figure represents the tensile test in progress. The figures to furnish below are specimens subjected to tensile test.

\begin{tabular}{|l|l|}
\hline Specimens & $\begin{array}{l}\text { Max } \\
\text { strength(MPa) }\end{array}$ \\
\hline Glass fiber epoxy & 305 \\
\hline Chaps ten E-glass epoxy & 194 \\
\hline $\begin{array}{l}\text { Glass fiber polyester } \\
\text { Epoxy }\end{array}$ & 65.8 \\
\hline
\end{tabular}

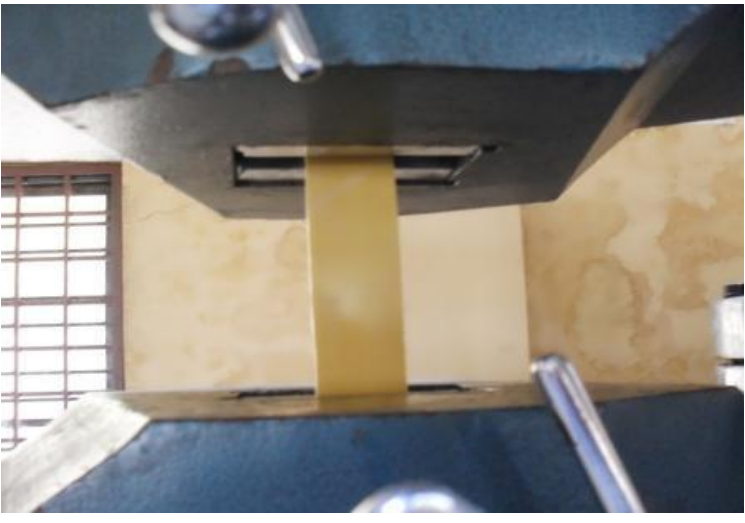

Table 1. Tensile Test Results

Fig. 9. Tensile Test in Process 


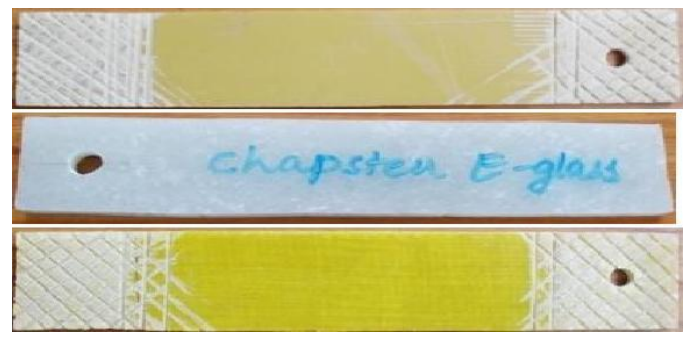

Fig. 10 Tensile Test Specimens of Glass Fiber Epoxy, Chapsten E-Glass Epoxy and Glass Fiber Polyester Epoxy

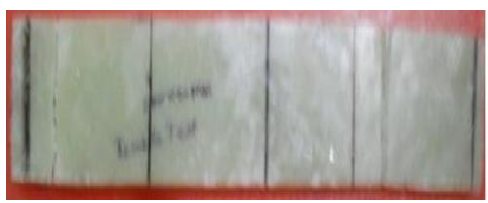

Fig. Glass Fiber Epoxy 10.1 Specimen after Tensile Test Fig. Glass Fiber Polyester Epoxy 10.3 Specimen after Tensile Test
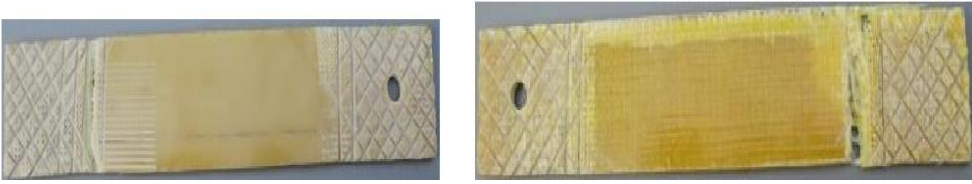

Fig $\quad 10.2$ Chapsten E-Glass Epoxy Specimen after Tensile Test

\section{RESULTS AND DISCUSSIONS}

\section{Introduction}

The present project work is aimed at establishing certain mechanical properties while designing fiber reinforced components for engineering applications. This experiment played an important role in estimation of stiffness of the laminate which in turn helps the user of the testing to evaluate the stiffness of the laminate for further mathematical purposes. The evaluating elastic properties and estimating the flexural stiffness of the composite beam and from the analytical evaluation of flexural stiffness has been matched with the theoretical calculations. This loss in stiffness of composite laminate is due to inherent defects generally occurs during welding and curing of the reinforced component.

This reduction in stiffness can further be improved by advanced manufacturing process such as compressor moulding and auto clave moulding and the results obtained from the analytical testing are used to calibrate the load transducers. The load transducer shows a linear response to the load from this is clearly evident that the testing could be able to generate the useful data for evaluating the fatigue failure behavior of the composites. This data acquisition load generates the digital of time verses voltage by converting this data into time verses voltage with suitable multiplying factors. The data acquisition system from standard manufacturer of model pci-207 which exactly meets requirements.

A continuous plot of time verses load could be obtained. We can say that the required data can be generated as per expectations, which could be utilized to establish the fatigue failure behavior any kind of composite laminate.

\subsection{Flexural Fatigue Failure Behaviour of Glass Fiber Epoxy Laminate}

Flexural fatigue failure behavior of laminates exhibits stiffness decay with respect to number cycles of load application. In this work ORIGIN LAB curve fitting tool is used to plot the data, number of cycles verses instantaneous maximum bending load within the cycle. The total scheme of experimentation is conducted at constant amplitude of bending. This phenomenon of bending load for yielding constant deflection is also known as stiffness. The test specimen used is shown in Fig. 7.1. 

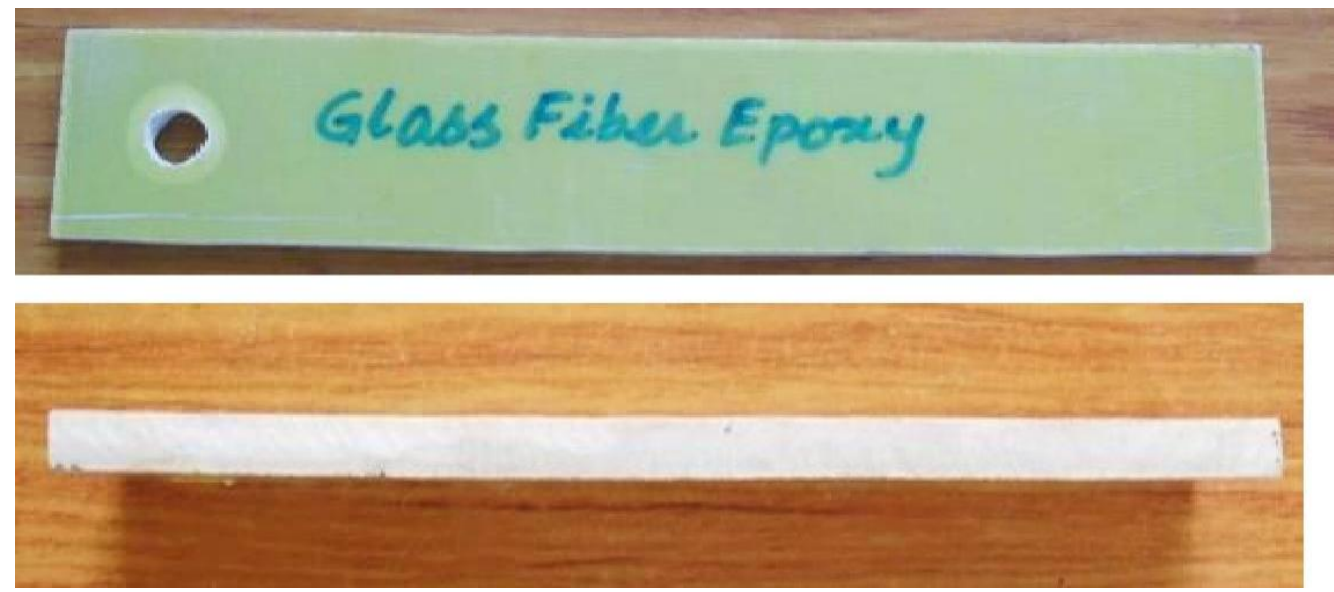

Fig.11. Glass Fiber Epoxy Test Specimen

From the data logging system, the converted data is load applied on the specimen and number of cycles is given in the table 7.1. This data is used in plotting stiffness degradation curves.

Table 2. Stiffness Degradation Data of Glass Fiber Epoxy laminate

\begin{tabular}{|l|l|}
\hline $\begin{array}{l}\text { Number of } \\
\text { Cycles }\end{array}$ & LOAD in \\
& NEWTONS \\
\hline 0 & 320.006 \\
\hline 100.48 & 311.663 \\
\hline 219.8 & 291.354 \\
\hline 345.4 & 281.055 \\
\hline 405.06 & 278.333 \\
\hline 538.51 & 278.356 \\
\hline 591.89 & 270.37 \\
\hline 676.67 & 267.555 \\
\hline 797.56 & 267.553 \\
\hline 904.32 & 264.895 \\
\hline 943.57 & 262.481 \\
\hline 1029.92 & 242.97 \\
\hline 1146.1 & 234.243 \\
\hline 1890.28 & 226.802 \\
\hline 2138.34 & 225.75 \\
\hline 2474.32 & 223.974 \\
\hline 2701.97 & 221.938 \\
\hline 279.65 & 219.28 \\
\hline 2824.43 & 206.40 \\
\hline 2964.16 & 198.321 \\
\hline & \\
\hline & \\
\hline & \\
\hline & \\
\hline & \\
\hline & \\
\hline & \\
\hline & \\
\hline & \\
\hline & \\
\hline & \\
\hline & \\
\hline & \\
\hline & \\
\hline & \\
\hline
\end{tabular}

\begin{tabular}{|l|l|}
\hline 5096.22 & 168.473 \\
\hline 5532.68 & 168.306 \\
\hline 4981.61 & 164.48 \\
\hline 6055.49 & 163.633 \\
\hline 6305.12 & 163.08 \\
\hline 6355.36 & 162.17 \\
\hline 6466.83 & 160.97 \\
\hline 6531.2 & 160.5 \\
\hline 6590.86 & 157.48 \\
\hline 6626.97 & 157.167 \\
\hline 6653.66 & 154.957 \\
\hline 6686.63 & 152.7 \\
\hline 6714.89 & 152.586 \\
\hline 6749.43 & 152.16 \\
\hline 6772.98 & 150.94 \\
\hline 6821.65 & 150.982 \\
\hline 7380.57 & 149333 \\
\hline 7567.4 & 148.687 \\
\hline 7892.4 & 145.935 \\
\hline 8262.91 & 145.701 \\
\hline 9700.94 & 142.19 \\
\hline 9679.7 & 140.777 \\
\hline & 137.973 \\
\hline
\end{tabular}

\begin{tabular}{|l|l|}
\hline 14894.6 & 116.910 \\
\hline 15305.93 & 114.223 \\
\hline 15769.08 & 113.781 \\
\hline 16552.51 & 113.09 \\
\hline 17397.17 & 113.046 \\
\hline 18012.61 & 111.728 \\
\hline 18552.7 & 108.632 \\
\hline 19196.4 & 104.075 \\
\hline 19915.45 & 100.07 \\
\hline 21078.82 & 95.11 \\
\hline 22000.41 & 88.041 \\
\hline 22564.04 & 87.966 \\
\hline 23242.28 & 84.687 \\
\hline 23831.03 & 83.902 \\
\hline 24287.9 & 77.38 \\
\hline 24689.82 & 73.771 \\
\hline 25170.24 & 70.9 \\
\hline 254865.1 & 68.147 \\
\hline 25906.57 & 67.971 \\
\hline 26602.08 & 65.935 \\
\hline 28164.23 & 65.16 \\
\hline & 63.473 \\
\hline & \\
\hline & \\
\hline & \\
\hline & \\
\hline & \\
\hline & \\
\hline & \\
\hline & \\
\hline & \\
\hline & \\
\hline & \\
\hline & \\
\hline & \\
\hline & \\
\hline & \\
\hline & \\
\hline
\end{tabular}

The data obtained from the experiments is plotted in plotted in Fig.11.1 Results obtained reveal that the nature of behavior of the material is revealing exponential decay in its mechanical properties due to fatigue. This type of plotting is normally known as "Stiffness Degradation Curve plotting". From the figure it is clear that the bending load is dropped from 
$320 \mathrm{~N}$ to $60.127 \mathrm{~N}$ and attained pivoting state where further reduction in stiffness is not noticed. Pivoting state is noticed at 25,000 cycles.
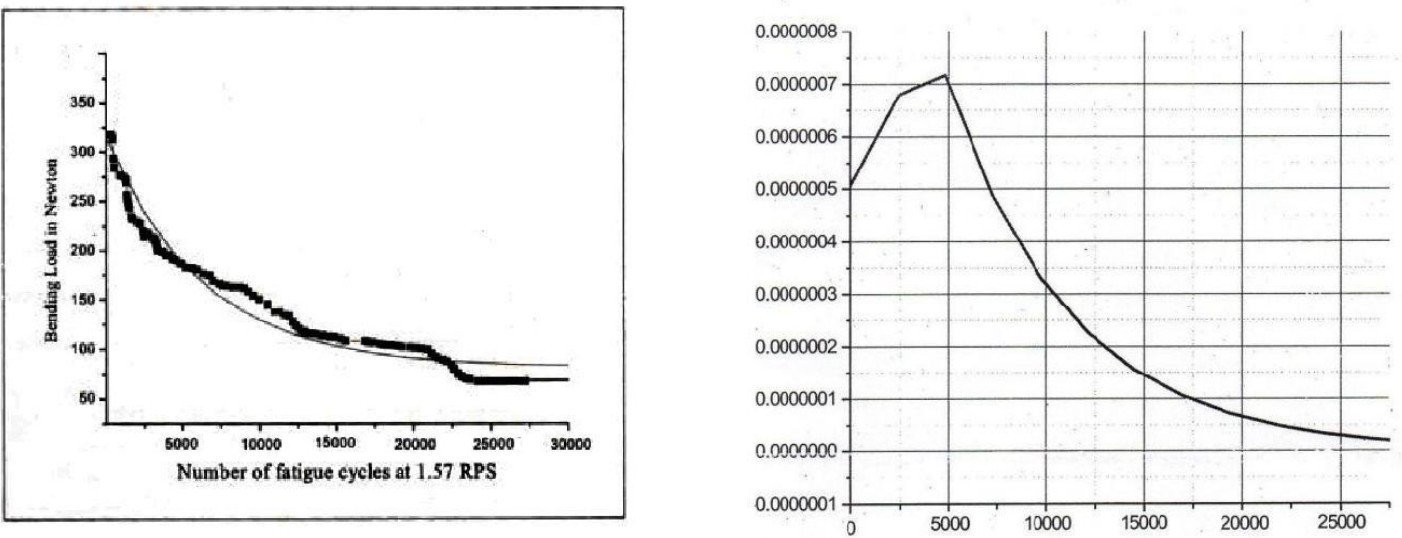

Fig. 11.1 Stiffness Degradation behaviour of Glass Fiber Epoxy laminate Number of Fatigue Cycles at 1.57 RPS for Glass Fiber Epoxy Laminate

Fig. 11.2 Second order differential curve of Glass Fiber Epoxy laminate derived from Fig.

\subsection{Flexural Fatigue Failure Behaviour of Chapsten E-Glass Epoxy Laminate}
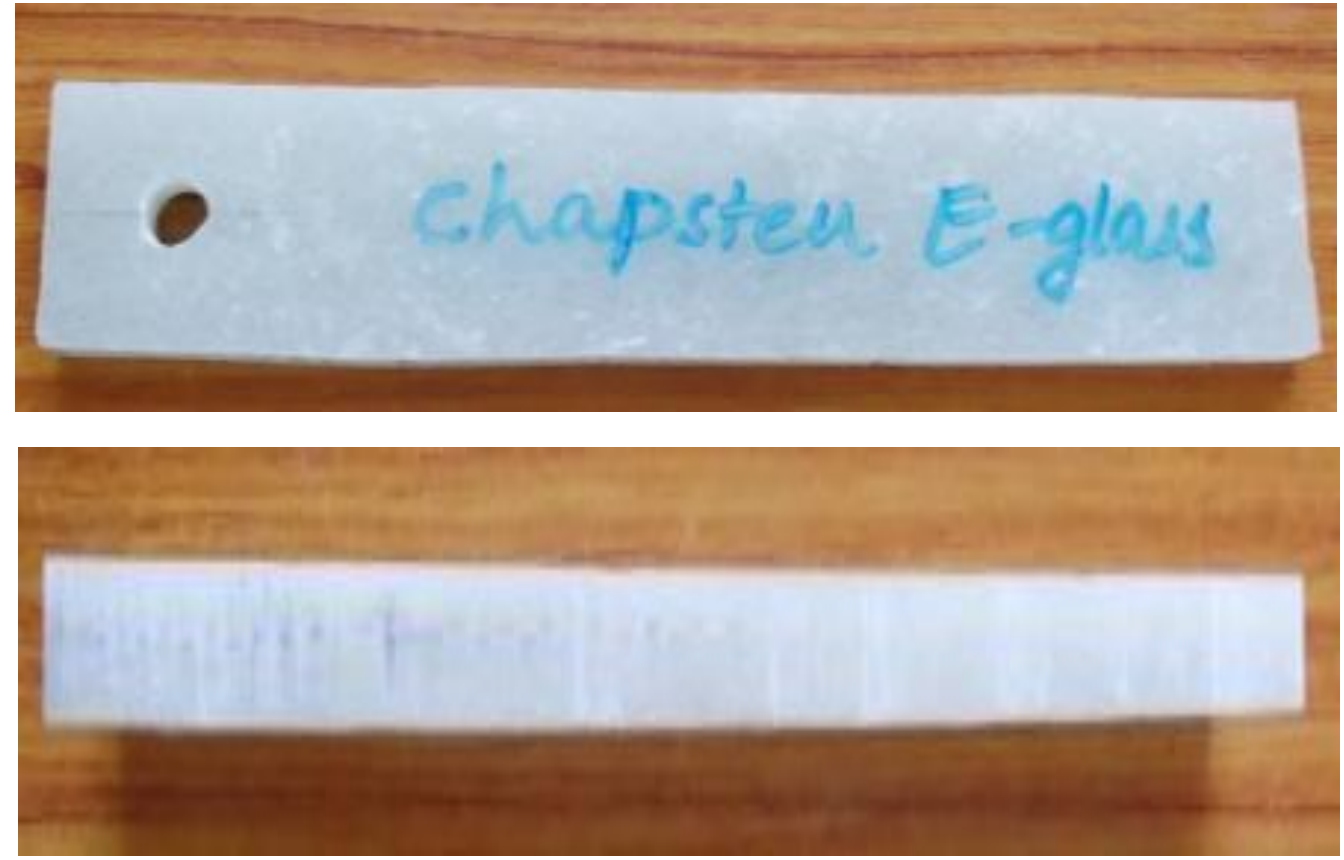

Fig. 12.Chapsten E-Glass Epoxy Test Specimen

The Flexural fatigue analysis data obtained from the experiment for Chapsten E-glass epoxy laminate is given in table 7.2. And the stiffness degradation is plotted in Fig.7.5. From this figure it is observed that the bending load dropped from $318.764 \mathrm{~N}$ to $27.416 \mathrm{~N}$. Compared to Glass fiber epoxy specimen stiffness degradation curve, it is observed that there is smooth reduction in stiffness. The stiffness at the pivoting state is $27.416 \mathrm{~N}$ as per the experiment. The stiffness of the specimen at the pivoting state is $8.6 \%$ of the virgin specimen. 
Table 3. Stiffness Degradation Data of Chapsten E-Glass Epoxy laminate

\begin{tabular}{|l|l|}
\hline $\begin{array}{l}\text { Number of } \\
\text { Cycles }\end{array}$ & $\begin{array}{l}\text { LOAD in } \\
\text { NEWTONS }\end{array}$ \\
\hline 0 & 318.764 \\
\hline 65.94 & 203.285 \\
\hline 202.53 & 122.103 \\
\hline 244.92 & 120.388 \\
\hline 281.03 & 119.051 \\
\hline 310.86 & 115.772 \\
\hline 438.03 & 110.53 \\
\hline 477.28 & 108.383 \\
\hline 507.11 & 107.142 \\
\hline 582.47 & 105.698 \\
\hline 610.73 & 104.392 \\
\hline 723.77 & 102.612 \\
\hline 761.45 & 101.331 \\
\hline 1339.21 & 98.353 \\
\hline 1734.85 & 97.95 \\
\hline 2391.11 & 97.62 \\
\hline 2634.46 & 97.21 \\
\hline 3367.65 & 96.73 \\
\hline 4461.94 & 94.842 \\
\hline
\end{tabular}

\begin{tabular}{|l|l|}
\hline 7353.88 & 79.787 \\
\hline 7523.44 & 74.421 \\
\hline 7656.89 & 71.113 \\
\hline 8247.21 & 68.1 \\
\hline 8597.32 & 65.6 \\
\hline 8685.24 & 54.7 \\
\hline 8859.51 & 47.73 \\
\hline 8913.43 & 46.77 \\
\hline 8962.47 & 45.356 \\
\hline 9014.62 & 44.756 \\
\hline 9452.74 & 43.9 \\
\hline 9924.73 & 42.235 \\
\hline 10732.22 & 41.766 \\
\hline 11219.35 & 40.565 \\
\hline 11763.48 & 39.96 \\
\hline 12132.83 & 38.91 \\
\hline 12764.03 & 38.565 \\
\hline 13217.72 & 38.223 \\
\hline 13741.35 & 37.881 \\
\hline 14264.98 & 37.54 \\
\hline 14788.61 & 37.2 \\
\hline 189454.02 & 34.801 \\
\hline 19501.28 & 34.12 \\
\hline 20024.91 & 33.775 \\
\hline 20548.54 & 33.433 \\
\hline 21072.17 & 33.091 \\
\hline 21595.8 & 32.75 \\
\hline 22119.43 & 32.406 \\
\hline 22643.06 & 32.064 \\
\hline 23166.69 & 31.722 \\
\hline 23690.32 & 31.38 \\
\hline 24213.95 & 31.04 \\
\hline 24755.32 & 30.7 \\
\hline 25296.69 & 30.354 \\
\hline 25838.06 & 30.112 \\
\hline 26379.43 & 29.67 \\
\hline 26290.8 & 29.33 \\
\hline 27462.17 & 28.985 \\
\hline 28003.54 & 28.643 \\
\hline 28544.91 & 28.3 \\
\hline 29086.28 & 27.96 \\
\hline
\end{tabular}
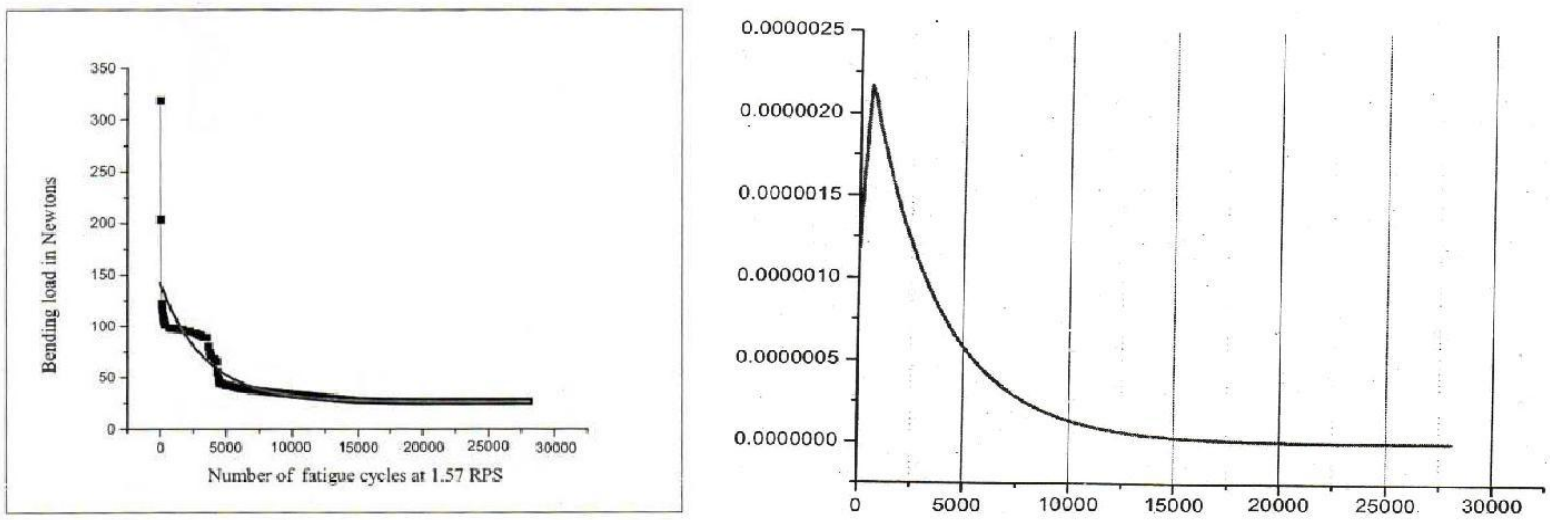

Fig. 12.1. Stiffness Degradation behaviour of Chapsten E-Glass Epoxy laminate Number of Fatigue Cycles at 1.57 RPS for Chapsten E-Glass Epoxy Laminate.

Fig. 12.2.Second order differential curve of Chapsten E-Glass Epoxy laminate derived from Fig. 12

The experiments carried out in the laminates of Glass Fiber Epoxy, Chapsten E-Glass Epoxy and Glass Fiber Polyester Epoxy clearly exhibited a variation in the residual load bearing capacity after pivoting state. The graphical representation in Fig. 12.1. The stiffness degradation process of each specimen under goes basically in three stages, in the first stage the stiffness reduction rate is very fast this is due to the top and bottom layers of the laminates are subjected to maximum strain which leads to the failure being the glass reinforcement is pure elastic in nature. In the second stage as the stress levels on the subsequent layers reduces as the distance from the neutral layer is continuously decreasing. In the third stage of the failure already broken fibers provides a cushioning effect and resist the free bending of the specimen hence the stiffness degradation tends to towards zero.

The results clearly establishes that the Glass Fiber Polyester Epoxy, exhibited very slow stiffness reduction rate when compared to the other specimens and the residual bending load bearing(residual stiffness ) is also maximum i.e. $58.617 \mathrm{~N}$ and the Stiffness retention after pivoting state is $73.26 \%$. Hence it can be recommends that the Glass Fiber Polyester Epoxy material is best for fatigue critical applications. 


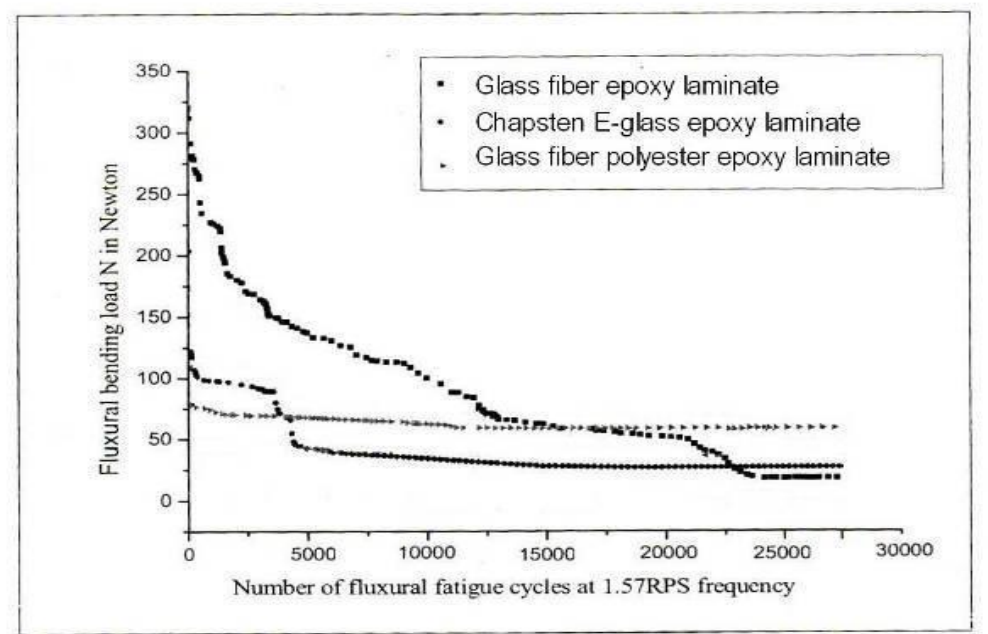

Fig. 12.3. Consolidated Flexural Fatigue Test Results of Glass Fiber Epoxy, Chapsten E-Glass Epoxy and Glass Fiber Polyester Epoxy laminates.

\section{CONCLUSION}

From the experimental investigation:

1. Flexural fatigue failure behavior of Glass Fiber Polyester Epoxy laminate composite exhibited better results.

2. The results clearly establish that the Glass Fiber Polyester Epoxy laminate exhibited very slow stiffness reduction rate when compared to the other specimens.

3. The residual bending load (residual stiffness) is also maximum i.e. $58 \mathrm{~N}$ and the Stiffness retention after pivoting state is $72.5 \%$ of the virgin specimen.

4. Hence it can be recommended that the Glass Fiber Polyester Epoxy laminate is good for flexural fatigue critical applications such as wind turbine blades, Air craft wing and auto motive leaf spring constructions.

\section{REFERENCES}

[1] Saud AldajahAmmar Al-omari and Ashraf Biddah Accelerated weathering effects on the mechanical and surface properties of CFRP composites Vernon T. Bechel, John D. Camping, Ran Y. Kim

[2] Cryogenic/elevated temperature cycling induced leakage paths in PMCs Composites Part B: Engineering, Volume 36, Issue 2, March 2005

[3] SandhyaRao, RMVGK Rao Cure studies on bifunctional epoxy matrices using a domestic microwave oven Polymer Testing, Volume 27, Issue 5, August 2008

[4] S. Birger, A. Moshonov, S. Kenig The effects of thermal and hygrothermal ageing on the failure mechanisms of graphite-fabric epoxy composites subjected to flexural loading Composites, Volume 20, Issue 4, July 1989

[5] Mechanical Properties Of Composite Material Using Natural Rubber With Epoxy Resin Dr. Hani Aziz Ameen 9/3/2008

[6] Fatigue Strength Assessment Of A Short Fibre-Reinforced Plastic Based On The Energy Dissipation G. Meneghetti*, M. Quaresimin**, M. De Monte**

[7] Experimentally Investigation Effect Of Geometrical Cross- Section On Fatigue Strength Of Aluminum Alloy (6063) Ghazi S. Al-Marahleh and KhaleelAbushgair Received: July 19, 2010

[8] Fatigue and Ultrasonic Testing of Epoxy-Glass Composites M. Rojek, J. Stabik*, S. Sokół

[9] Mechanical Measurements by Thomas G.Beckwith, Roy D. Marangoni, John H. Lienhard Fifth edition an imprint of Addison Wesley Longman, Inc First ISE reprint 1999

[10] The Pressure and Strain Handbook, Vol.29, Omega Engineering. 